\title{
Response Surface Grey Relational Analysis On The Manufacturing of High Grade Biomedical Ti-13Zr- $13 \mathrm{Nb}$
}

Johnson Kehinde Abifarin ( $\nabla$ abifarinjohnsonk@yahoo.com )

Ahmadu Bello University

Fredah Batale Fidelis

Ahmadu Bello University

Moshood Yemi Abdulrahim

Ahmadu Bello University

Elijah Oyewusi Oyedeji

National Space Research and Development Agency (NASRDA)

Tochukwu Nkwuo

Scientific Equipment Development Institute (SEDI)

Chander Prakash

Lovely Professional University

\section{Research Article}

Keywords: titanium alloy, Central Composite Design, biomedical engineering, grey relational analysis, optimization, mathematical modeling

Posted Date: January 6th, 2022

DOI: https://doi.org/10.21203/rs.3.rs-1225030/v1

License: (c) (i) This work is licensed under a Creative Commons Attribution 4.0 International License. Read Full License 


\section{Abstract}

Optimization of the manufacturing conditions with more than one performance characteristics have been a thing of concern, especially for Response Surface Method (RSM) optimization. Hence, this study addressed this challenge by reanalyzing a data presented in a previous study using grey relational analysis (GRA) and regression analysis. Central Composite Design (CCD) of RSM with high and low values of manufacturing conditions; voltage $(50,70) \mathrm{V}$, current $(8,16) \mathrm{A}$, pulse ON time $(6,10) \mu s$, and pulse OFF time $(7,11) \mu s$. The manufacturing conditions for optimal biomedical Ti-13Zr-13Nb alloy were obtained to be $50 \mathrm{~V}$ voltage, $8 \mathrm{~A}$ current, $6 \mu \mathrm{s}$ pulse $\mathrm{ON}$ time, and $11 \mu \mathrm{s}$ pulse OFF time. It was also revealed that the mathematical model was very efficient because the modeled GRG was in consonant with the experimental one. In addition, it was also established that current was the most significant manufacturing condition with a contribution of $47.27 \%$. Voltage, factors interactions and residual error were insignificant on the GRG value of the titanium alloy. In conclusion, it can be deduced that the a small value of voltage within the considered settings could be used to manufacture better grade Ti-13Zr- $13 \mathrm{Nb}$ alloy and also the small value of residual error showed the high manufacturability of the material.

\subsection{Introduction}

It has been shown consistently that traditional machining method has been inefficient and cumbersome in the manufacturing of a material with high strength and high temperature resistance capacity (Rizwee et al., 1807; Soundhar et al., 2019; Rizwee et al., 2020; Singaravel et al., 2020; Boopathi, 2022). Ti-13Zr$13 \mathrm{Nb}$ is a titanium alloy very suitable for bone implant (Shah et al., 2017; Soundhar et al., 2019; Majchrowicz et al., 2019; Ossowska et al., 2020; Kumar et al., 2021) and its fabrication quite demanding compared to other materials because of its mechanical strength and the required complex shape for biomedical implant. Electrical discharge machining method (EDM) has replaced the traditional method in the manufacturing of a complex shape and high strength material due to its high manufacturing efficiency (Zia et al., 2019; Myilsamy \& Sampath, 2021). Many studies have been conducted on the use of EDM for the manufacturing of material, to mention few as follows. Świercz \& Oniszczuk-Świercz (2017) machined tool steel with EDM and investigated the surface layer properties of the tool steel. Garg \& Sharma (2017) examined how accurate the EDM method was in the manufacturing of metal matrix composite (MMC). Gowthaman et al. (2018) made a study on the employement of EDM in machining monel-super alloy. Kavimani et al. (2019) investigated the influence of EDM parameters on surface integrity of reduced graphene oxide/magnesium composite. Muthuramalingam (2019) examined the effect of discharge energy on white layer thickness of EDM process. Grigoriev et al. (2020) studied the machining of oxide nanocomposite using EDM technique. Ming et al. (2021) studied how to minimize energy consumption and exhaust emissions during the machining of Al 6061 and SKD 11 when with EDM technique. Despite several studies on the use of EDM in the manufacturing of materials, optimization of machining conditions for multiple performance characteristics has been a point of concern. This studies employed the use of grey relational analysis as a unique assistance for response surface methodology. 
Response surface method (RSM) is a collection of mathematical and statistical techniques for exploring the relationships between several inputs as design variables and one or more response variables as an outcome. RSM uses a sequence of suitably designed experiments to fnd an optimal response that is only an approximation of experimental model. This approximated model is adequate to estimate and apply, even when little is known about the process. Statistical and mathematical approaches such as RSM can be used to extract a model that present optimized operational factors (Dadrasi et al., 2019). Although there have been several studies in the fabrication of biomedical materials, such as bioceramics (Obada et al., 2020; Abifarin et al., 2019; Abifarin, 2021; Obada et al., 2021a; Obada et al., 2021b; Abifarin et al., 2021a; Abifarin et al., 2021b); biodegradable polymers (Oladapo et al., 2019; Tafaoli-Masoule et al., 2019; Oladapo et al., 2021a; Abifarin et al., 2021c; Oladapo \& Zahedi, 2021; Oladapo et al., 2021b; Oladapo et al., 2021c); biocompatible metallic implants (Montani et al., 2017; Prakash \& Uddin, 2017; Prakash et al., 2018; Prakash et al., 2019; Prakash et al., 2020), these studies had relatively insufficient information in the employment of optimization techniques for a lasting solution in the fabrication of biomedical materials, especially metallic implants like Ti alloy. Stanić et al. (2014) employed CCD technique to optimize operating conditions of antimicrobial activity for the synthesized fluorine doped HAp (FHAP). The operating conditions considered were exposure time, $\mathrm{pH}$ of saline, and fluoride concentration and fluoride concentration in apatite samples. The design revealed that there was close agreement in antimicrobial activities of both the experimental and the predicted results. It was further revealed that reduction in $\mathrm{pH}$ salinity and increase in fluoride concentration enhanced antimicrobial activities of the synthesized FHAp. Farombi et al. (2018) prepared catfish derived HAp (CHAp) at optimized synthesis conditions, namely; temperature $\left(300-1000^{\circ} \mathrm{C}\right)$, heating time (1-2 h)s using CCD. It was revealed from the design that optimization of the synthesis conditions for quality HAp was gotten. Eosoly et al. (2010) fabricated poly- $\varepsilon$-caprolactone doped HAp (PHAp) and used CCD technique to optimize laser fill power, outline laser power, scan spacing, and part orientation for high performance PHAp. The obtained result from the design revealed that the fabricated HAp depends on the manufacturing direction and scan spacing. It was further established from the result that the mechanical behavior was a function of manufacturing direction. Foroutan et al. (2020) employed CCD to investigate the effect of $\mathrm{pH}(2-10)$, temperature $\left(25-45^{\circ} \mathrm{C}\right)$, contact time (10-50 min), initial methyl violet (MV) concentration (5-25 mg/L), and Bio-HAp/MgO quantity (0.5-2.5g/L) on the composite adsorption efficiency. It was revealed that Bio$\mathrm{HAp}$ particles and Bio-HAp/MgO mesoporous composites efficiently reduced the dye content of the pure sample. Pathak \& Pandey (2020) employed pressure-less microwave sintering assisted by CCD technique to fabricate zinc-hydroxyapatite (ZHAp) biodegradable composite for load bearing orthopedic application. The CCD was used to investigate the effect and to optimize process factors, namely; $w t \%$ of hydroxyapatite, compaction pressure, and microwave sintering factors such as sintering temperature, heating rate, and soaking time on the compressive yield strength and sintered density. The regression analysis in the CCD technique brought out the optimum processing conditions and the conditions were validated through confirmation analysis. It was further noted that the fabricated ZHAp correlated with the human native bone required mechanical and degradation characteristics. Ebrahimi et al. (2021) employed CCD to optimize $\mathrm{pH}$, temperature, and hydrothermal treatment time for high yield, size, and crystallinity. It was observed that pH is the most influencing factor affecting the yield, size, and 
crystallinity of the synthesized HAp. Fern \& Salimi (2021) employed CCD technique to examine the effect of processing temperatures $\left(30-50^{\circ} \mathrm{C}\right)$, stirring time (30-60 min) and stirring rates (300-500 rpm) on the crystallite size of HAp. The variance analysis from the design revealed $\mathrm{R}^{2}$ coefficient to be 0.8736 and established processing temperature to be the most influencing factor affecting the crystallite size of HAp. Coşkun et al. (2016) employed CCD technique to examine the effect of solution temperature and applied potential on the in vitro corrosion performance of hydroxyapatite coated CoCrMo biomedical alloys. The experimental processing conditions were temperature $\left(10-74^{\circ} \mathrm{C}\right)$ and potential $(-1.2-1.9 \mathrm{~V})$. The result revealed that the predicted and experimental values correlated with an $R^{2}$ value of 0.9481 . The optimized processing conditions were obtained to $32.33^{\circ} \mathrm{C}$ solution temperature and $-1.55 \mathrm{~V}$ potential. It was also noted that the HAp coated CoCrMo alloys at optimum conditions displayed excellent crystal formation and high in vitro corrosion resistance.

Grey relational analysis technique has been proven to assist a complex situation and to determine the optimal manufacturing conditions for multiple performance characteristics (Yazdani et al., 2019; Li et al., 2019; Abifarin, 2021). Hence, this study employed grey relational analysis to assist response surface optimization analysis in the manufacturing of Ti-13Zr-13Nb alloy.

\subsection{Research Methodology}

This study employed a data from Data in Brief article by Soundhar et al. (2019). The data was only presented and analyzed using response surface methodology for individual response optimization. However, this study optimized multiple responses for better manufacturing conditions with the assistance of grey relational analysis. Table 1 shows the manufacturing conditions employed in the analysis. The analysis was done using central composite design (CCD) and it is as shown in Table 2. The breakdown of the experimental run and data are also displayed in in Table 3 and Table 4, respectively. The multiple responses considered for the optimization of the manufacturing of Ti-13Zr-13Nb alloy are electrode wear rate (EWR), surface roughness (SR), and material removal rate (MRR).

Table 1

Manufacturing conditions

\begin{tabular}{|llll|}
\hline Acronyms & Manufacturing conditions & Low level & High level \\
\hline A & Voltage $(\mathrm{V})$ & 50 & 70 \\
\hline B & Current $(\mathrm{A})$ & 8 & 16 \\
\hline C & Pulse ON time $(\mu s)$ & 6 & 10 \\
\hline D & Pulse OFF time $(\mu s)$ & 7 & 11 \\
\hline
\end{tabular}


Table 2

Central Composite Design (CCD) details

\begin{tabular}{|llllll|}
\hline \multicolumn{7}{|l|}{ Central composite design (CCD) } & & \\
\hline Factors & Base runs & $\begin{array}{l}\text { Base } \\
\text { blocks }\end{array}$ & Replicates & $\begin{array}{l}\text { Total } \\
\text { runs }\end{array}$ & $\begin{array}{l}\text { Total } \\
\text { blocks }\end{array}$ \\
\hline 4 & 30 & 3 & 1 & 30 & 3 \\
\hline $\begin{array}{l}\text { Cube } \\
\text { points }\end{array}$ & $\begin{array}{l}\text { Center points in } \\
\text { cube }\end{array}$ & $\begin{array}{l}\text { Axial } \\
\text { points }\end{array}$ & $\begin{array}{l}\text { Cube points in } \\
\text { axial }\end{array}$ & Alpha & \\
\hline 16 & 4 & 8 & 2 & 1 & \\
\hline
\end{tabular}


Table 3

Experimental design run

\begin{tabular}{|c|c|c|c|c|c|c|c|c|}
\hline Run & StdOrder & RunOrder & PtType & Blocks & Voltage & Current & $\begin{array}{l}\text { Pulse ON } \\
\text { time }\end{array}$ & $\begin{array}{l}\text { Pulse OFF } \\
\text { time }\end{array}$ \\
\hline 1 & 9 & 1 & 0 & 1 & 60 & 12 & 8 & 9 \\
\hline 2 & 5 & 2 & 1 & 1 & 50 & 8 & 6 & 11 \\
\hline 3 & 8 & 3 & 1 & 1 & 50 & 16 & 10 & 11 \\
\hline 4 & 4 & 4 & 1 & 1 & 70 & 16 & 10 & 7 \\
\hline 5 & 1 & 5 & 1 & 1 & 70 & 8 & 6 & 7 \\
\hline 6 & 10 & 6 & 0 & 1 & 60 & 12 & 8 & 9 \\
\hline 7 & 6 & 7 & 1 & 1 & 70 & 16 & 6 & 11 \\
\hline 8 & 2 & 8 & 1 & 1 & 50 & 16 & 6 & 7 \\
\hline 9 & 3 & 9 & 1 & 1 & 50 & 8 & 10 & 7 \\
\hline 10 & 7 & 10 & 1 & 1 & 70 & 8 & 10 & 11 \\
\hline 11 & 30 & 11 & 0 & 3 & 60 & 12 & 8 & 9 \\
\hline 12 & 27 & 12 & -1 & 3 & 60 & 12 & 8 & 7 \\
\hline 13 & 21 & 13 & -1 & 3 & 50 & 12 & 8 & 9 \\
\hline 14 & 24 & 14 & -1 & 3 & 60 & 16 & 8 & 9 \\
\hline 15 & 22 & 15 & -1 & 3 & 70 & 12 & 8 & 9 \\
\hline 16 & 29 & 16 & 0 & 3 & 60 & 12 & 8 & 9 \\
\hline 17 & 25 & 17 & -1 & 3 & 60 & 12 & 6 & 9 \\
\hline 18 & 28 & 18 & -1 & 3 & 60 & 12 & 8 & 11 \\
\hline 19 & 26 & 19 & -1 & 3 & 60 & 12 & 10 & 9 \\
\hline 20 & 23 & 20 & -1 & 3 & 60 & 8 & 8 & 9 \\
\hline 21 & 14 & 21 & 1 & 2 & 50 & 16 & 10 & 7 \\
\hline 22 & 20 & 22 & 0 & 2 & 60 & 12 & 8 & 9 \\
\hline 23 & 15 & 23 & 1 & 2 & 70 & 8 & 6 & 11 \\
\hline 24 & 17 & 24 & 1 & 2 & 50 & 8 & 10 & 11 \\
\hline 25 & 18 & 25 & 1 & 2 & 70 & 16 & 10 & 11 \\
\hline 26 & 19 & 26 & 0 & 2 & 60 & 12 & 8 & 9 \\
\hline
\end{tabular}




\begin{tabular}{|lllllllll|}
\hline Run & StdOrder & RunOrder & PtType & Blocks & Voltage & Current & $\begin{array}{l}\text { Pulse ON } \\
\text { time }\end{array}$ & $\begin{array}{l}\text { Pulse OFF } \\
\text { time }\end{array}$ \\
\hline 27 & 11 & 27 & 1 & 2 & 50 & 8 & 6 & 7 \\
\hline 28 & 12 & 28 & 1 & 2 & 70 & 16 & 6 & 7 \\
\hline 29 & 16 & 29 & 1 & 2 & 50 & 16 & 6 & 11 \\
\hline 30 & 13 & 30 & 1 & 2 & 70 & 8 & 10 & 7 \\
\hline
\end{tabular}


Table 4

Experimental data

\begin{tabular}{|llll|}
\hline Run & MRR (g/min) & EWR (g/min) & SR (um) \\
\hline 1 & 0.4731 & 0.006 & 10.325 \\
\hline 2 & 0.5075 & 0.0004 & 6.245 \\
\hline 3 & 0.525 & 0.0107 & 16.758 \\
\hline 4 & 0.4086 & 0.0133 & 14.814 \\
\hline 5 & 0.0789 & 0.004 & 7.647 \\
\hline 6 & 0.4482 & 0.008 & 15.851 \\
\hline 7 & 0.086 & 0.004 & 10.168 \\
\hline 8 & 0.2193 & 0.008 & 10.008 \\
\hline 9 & 0.2004 & 0.0039 & 13.289 \\
\hline 10 & 1.0208 & 0.0036 & 14.322 \\
\hline 11 & 0.4572 & 0.007 & 12.485 \\
\hline 12 & 0.322 & 0.008 & 10.008 \\
\hline 13 & 0.205 & 0.0076 & 12.629 \\
\hline 14 & 0.5707 & 0.0101 & 11.728 \\
\hline 15 & 0.2412 & 0.0085 & 18.214 \\
\hline 16 & 0.441 & 0.005 & 14.867 \\
\hline 17 & 0.34 & 0.0044 & 7.545 \\
\hline 18 & 0.6305 & 0.0057 & 12.196 \\
\hline 19 & 0.6162 & 0.007 & 13.608 \\
\hline 20 & 0.7129 & 0.0041 & 9.149 \\
\hline 21 & 0.2574 & 0.0115 & 14.514 \\
\hline 22 & 0.4623 & 0.017 & 16.24 \\
\hline 23 & 0.4272 & 0.0004 & 9.04 \\
\hline 24 & 1.051 & 0.0043 & 10.389 \\
\hline 25 & 0.616 & 0.0117 & 14.514 \\
\hline 26 & 0.473 & 0.007 & 14.717 \\
\hline 27 & 0.099 & 0.0042 & 6.301 \\
\hline
\end{tabular}




\begin{tabular}{|llll|}
\hline Run & MRR (g/min) & EWR (g/min) & SR (um) \\
\hline 28 & 0.3206 & 0.0105 & 9.577 \\
29 & 0.0448 & 0.003 & 6.753 \\
30 & 0.23 & 0.003 & 11.558 \\
\hline
\end{tabular}

\subsection{Data Analysis}

The multiple responses optimization was done using grey relational analysis. First, the data was normalized using equation 1 and 2 . The higher-the-better (equation 1) was chosen to normalize MRR because as high as possible metal removal rates was desired, while the smaller-the-better (equation 2) was chosen for EWR and SR because minimization was desired for both.

$$
x_{i}(k)=\frac{y_{i}(k)-\min _{i}(k)}{\operatorname{maxy}_{i}(k)-\min _{i}(k)}
$$

1

$$
x_{i}(k)=\frac{\max _{i}(k)-y_{i}(k)}{\operatorname{maxy}_{i}(k)-\min _{i}(k)}
$$

Note that $x_{i}(k)$ is the normalized of the ith experiment, and $y_{i}(k)$ is the initial data of the mean of each response.

Next, deviation data sequence was calculated using equation 3 . The normalized data and the deviation data sequence are presented in Table 5

$\Delta_{o i}(k)=\left\|\mathrm{x}_{\mathrm{o}}(\mathrm{k})-\mathrm{x}_{\mathrm{i}}(\mathrm{k})\right\|$

Note that $\Delta_{o i}(k), \mathrm{x}_{\mathrm{o}}(\mathrm{k})$, and $\mathrm{x}_{\mathrm{i}}(\mathrm{k})$ are the deviation data sequence and the ideal data sequence, respectively. 
Table 5

Normalized data and deviation data sequence

\begin{tabular}{|c|c|c|c|c|c|c|}
\hline \multirow[t]{2}{*}{ Run } & \multicolumn{3}{|c|}{ Normalized data } & \multicolumn{3}{|c|}{ Deviation sequence } \\
\hline & MRR (g/min) & EWR (g/min) & SR (um) & MRR (g/min) & EWR (g/min) & SR (um) \\
\hline 1 & 0.425661 & 0.662651 & 0.659119 & 0.574339 & 0.337349 & 0.340881 \\
\hline 2 & 0.459849 & 1 & 1 & 0.540151 & 0 & 0 \\
\hline 3 & 0.477241 & 0.379518 & 0.121648 & 0.522759 & 0.620482 & 0.878352 \\
\hline 4 & 0.361558 & 0.222892 & 0.284067 & 0.638442 & 0.777108 & 0.715933 \\
\hline 5 & 0.03389 & 0.783133 & 0.882864 & 0.96611 & 0.216867 & 0.117136 \\
\hline 6 & 0.400914 & 0.542169 & 0.197427 & 0.599086 & 0.457831 & 0.802573 \\
\hline 7 & 0.040946 & 0.783133 & 0.672237 & 0.959054 & 0.216867 & 0.327763 \\
\hline 8 & 0.173425 & 0.542169 & 0.685604 & 0.826575 & 0.457831 & 0.314396 \\
\hline 9 & 0.154641 & 0.789157 & 0.41148 & 0.845359 & 0.210843 & 0.58852 \\
\hline 10 & 0.969986 & 0.807229 & 0.325173 & 0.030014 & 0.192771 & 0.674827 \\
\hline 11 & 0.409859 & 0.60241 & 0.478653 & 0.590141 & 0.39759 & 0.521347 \\
\hline 12 & 0.275492 & 0.542169 & 0.685604 & 0.724508 & 0.457831 & 0.314396 \\
\hline 13 & 0.159213 & 0.566265 & 0.466622 & 0.840787 & 0.433735 & 0.533378 \\
\hline 14 & 0.52266 & 0.415663 & 0.5419 & 0.47734 & 0.584337 & 0.4581 \\
\hline 15 & 0.19519 & 0.512048 & 0 & 0.80481 & 0.487952 & 1 \\
\hline 16 & 0.393759 & 0.722892 & 0.279639 & 0.606241 & 0.277108 & 0.720361 \\
\hline 17 & 0.293381 & 0.759036 & 0.891386 & 0.706619 & 0.240964 & 0.108614 \\
\hline 18 & 0.582091 & 0.680723 & 0.502799 & 0.417909 & 0.319277 & 0.497201 \\
\hline 19 & 0.567879 & 0.60241 & 0.384827 & 0.432121 & 0.39759 & 0.615173 \\
\hline 20 & 0.663983 & 0.777108 & 0.757373 & 0.336017 & 0.222892 & 0.242627 \\
\hline 21 & 0.21129 & 0.331325 & 0.309132 & 0.78871 & 0.668675 & 0.690868 \\
\hline 22 & 0.414927 & 0 & 0.164926 & 0.585073 & 1 & 0.835074 \\
\hline 23 & 0.380044 & 1 & 0.76648 & 0.619956 & 0 & 0.23352 \\
\hline 24 & 1 & 0.76506 & 0.653772 & 0 & 0.23494 & 0.346228 \\
\hline 25 & 0.56768 & 0.319277 & 0.309132 & 0.43232 & 0.680723 & 0.690868 \\
\hline 26 & 0.425562 & 0.60241 & 0.292171 & 0.574438 & 0.39759 & 0.707829 \\
\hline
\end{tabular}




\begin{tabular}{|lllllll|}
\hline Run & \multicolumn{2}{l}{ Normalized data } & \multicolumn{4}{l|}{ Deviation sequence } \\
\cline { 2 - 7 } & MRR (g/min) & EWR (g/min) & SR (um) & MRR (g/min) & EWR (g/min) & SR (um) \\
\hline 27 & 0.053866 & 0.771084 & 0.995321 & 0.946134 & 0.228916 & 0.004679 \\
\hline 28 & 0.274101 & 0.391566 & 0.721614 & 0.725899 & 0.608434 & 0.278386 \\
\hline 29 & 0 & 0.843373 & 0.957557 & 1 & 0.156627 & 0.042443 \\
\hline 30 & 0.184059 & 0.843373 & 0.556103 & 0.815941 & 0.156627 & 0.443897 \\
\hline
\end{tabular}

Afterwards, the grey relational coefficient (GRC) was calculated using equation 4.

$$
\xi_{i}(k)=\frac{\Delta_{\min }+\zeta \Delta_{\max }}{\Delta_{o i}(k)+\zeta \Delta_{\max }}
$$

4

Note that $\xi_{i}(k)$ is the GRC responses calculated, which is in terms of $\Delta_{\min }$ and $\Delta_{\max }$ the smallest and the highest deviation data. $\zeta$ denotes distinguishing coefficient $(0 \sim 1)$, but a coefficient of 0.5 is normally allotted.

Next, the grey relational grade (GRG) was calculated using equation 5 , then the ranking was done based on the amount of GRG values. The GRC, GRG values and the ranking are presented in Table 6 . The run with the highest GRG value is the optimal setting for the manufacturing of biomedical Ti-13Zr-13Nb alloy.

$$
\gamma_{i}=\frac{1}{n} \sum_{i=1}^{n} \xi_{i}(k)
$$

5

Note that $\gamma_{i}$ denotes GRG values for the ith experiment, $\mathrm{n}$ is the combined count of the responses. 
Table 6

GRC, GRG and ranking

\begin{tabular}{|c|c|c|c|c|c|}
\hline \multirow[t]{2}{*}{ Run } & \multicolumn{3}{|c|}{ Grey relational coefficient (GRC) } & \multirow[t]{2}{*}{ GRG } & \multirow[t]{2}{*}{ Rank } \\
\hline & MRR (g/min) & EWR (g/min) & SR (um) & & \\
\hline 1 & 0.465402 & 0.597122 & 0.594615 & 0.55238 & 11 \\
\hline 2 & 0.480699 & 1 & 1 & 0.8269 & 1 \\
\hline 3 & 0.488874 & 0.446237 & 0.362752 & 0.432621 & 26 \\
\hline 4 & 0.439197 & 0.391509 & 0.411207 & 0.413971 & 27 \\
\hline 5 & 0.341039 & 0.697479 & 0.810194 & 0.616237 & 9 \\
\hline 6 & 0.454924 & 0.522013 & 0.383856 & 0.453597 & 25 \\
\hline 7 & 0.342688 & 0.697479 & 0.604037 & 0.548068 & 13 \\
\hline 8 & 0.37691 & 0.522013 & 0.613952 & 0.504292 & 17 \\
\hline 9 & 0.371648 & 0.70339 & 0.459339 & 0.511459 & 16 \\
\hline 10 & 0.943371 & 0.721739 & 0.425595 & 0.696902 & 4 \\
\hline 11 & 0.458656 & 0.557047 & 0.48955 & 0.501751 & 18 \\
\hline 12 & 0.408327 & 0.522013 & 0.613952 & 0.514764 & 14 \\
\hline 13 & 0.372915 & 0.535484 & 0.48385 & 0.464083 & 23 \\
\hline 14 & 0.511592 & 0.461111 & 0.521866 & 0.49819 & 21 \\
\hline 15 & 0.383198 & 0.506098 & 0.333333 & 0.407543 & 29 \\
\hline 16 & 0.451981 & 0.643411 & 0.409715 & 0.501702 & 19 \\
\hline 17 & 0.414381 & 0.674797 & 0.821539 & 0.636906 & 8 \\
\hline 18 & 0.544716 & 0.610294 & 0.501403 & 0.552138 & 12 \\
\hline 19 & 0.536411 & 0.557047 & 0.448361 & 0.51394 & 15 \\
\hline 20 & 0.598074 & 0.691667 & 0.673286 & 0.654342 & 7 \\
\hline 21 & 0.387985 & 0.427835 & 0.419862 & 0.411894 & 28 \\
\hline 22 & 0.460799 & 0.333333 & 0.374511 & 0.389548 & 30 \\
\hline 23 & 0.446446 & 1 & 0.681645 & 0.709364 & 3 \\
\hline 24 & 1 & 0.680328 & 0.590857 & 0.757062 & 2 \\
\hline 25 & 0.536297 & 0.423469 & 0.419862 & 0.459876 & 24 \\
\hline 26 & 0.465359 & 0.557047 & 0.413966 & 0.478791 & 22 \\
\hline
\end{tabular}




\begin{tabular}{|llllll|}
\hline \multirow{2}{*}{ Run } & \multicolumn{2}{l}{ Grey relational coefficient (GRC) } & \multirow{2}{*}{ GRG } & Rank \\
\cline { 2 - 4 } & MRR (g/min) & EWR (g/min) & SR (um) & & \\
\hline 27 & 0.345749 & 0.68595 & 0.990729 & 0.674143 & 5 \\
\hline 28 & 0.407864 & 0.451087 & 0.642355 & 0.500435 & 20 \\
\hline 29 & 0.333333 & 0.761468 & 0.921756 & 0.672186 & 6 \\
\hline 30 & 0.379956 & 0.761468 & 0.529719 & 0.557048 & 10 \\
\hline
\end{tabular}

\subsection{Discussion Of Results}

\subsection{Optimal settings determination}

As it was mentioned that the experimental run with the highest GRG value which was ranked number 1 is the optimal setting to manufacture high grade biomedical Ti-13Zr-13Nb alloy. The $2 \mathrm{nd}$ run displayed the highest GRG value, and it is properly presented in Fig. 1. Based on the reflections in Table 3, the 2nd experimental run has the manufacturing conditions at $50 \mathrm{~V}$ voltage, $8 \mathrm{~A}$ current, $6 \mu \mathrm{s}$ pulse $\mathrm{ON}$ time, $11 \mu \mathrm{s}$ pulse OFF time. This conclusively gave the optimal settings for a sustainable manufacturing of Ti-13Zr$13 \mathrm{Nb}$ alloy compared to the work of Soundhar et al. (2019). Soundhar et al. (2019) only presented optimal settings for all the three individual responses which were not the same, however the present study mitigated the complex situations presented in the previous study.

\subsection{Mathematical modeling and interaction of manufacturing conditions}

The mathematical model of the manufacturing conditions for GRG values are presented in equation 6 using regression analysis. The modeled GRG data corresponding to its respective experimental data is presented in Fig. 2. The modeled data generated from equation 6 which is presented in Fig. 2 shows the same behavioral pattern with the experimental data. This shows the efficacy of the mathematical model. The interaction of the manufacturing conditions relative to its corresponding GRG is also presented in Fig. 3. This shows how combinations of manufacturing conditions can give a desired GRG value.

$G R G=0.892-0.00192 A-0.0217 B-0.0259 C+0.0264 D(6)$

\subsection{Significance of manufacturing conditions}

Table 7 reflects the analysis of variance (ANOVA) which highlights the contributions of each factor and their interactions on the GRG values. The factor B (Current) reflects the most contributing factor, having $47.27 \%$, followed by pulse OFF time. This is better described in Fig. 4. The results revealed that Voltage, interactions and residual error were not significant on the GRG values. In other words, minimum value of 
voltage could produce excellent results and also the insignificance of the residual error shows high manufacturability of Ti-13Zr-13Nb alloy.

Table 7

Analysis of variance

\begin{tabular}{|llllll|}
\hline Source & DF & Seq SS & Adj MS & F & \% of Contribution \\
\hline A & 1 & 0.00662 & 0.0062 & 3.43 & 2.16 \\
\hline$B$ & 1 & 0.135534 & 0.135534 & 70.31 & 47.27 \\
\hline C & 1 & 0.048439 & 0.048439 & 25.53 & 16.89 \\
\hline$D$ & 1 & 0.050231 & 0.050231 & 26.06 & 17.52 \\
\hline$A^{*} B$ & 1 & 0.000522 & 0.000522 & 0.27 & 0.18 \\
\hline$A^{*} C$ & 1 & 0.006327 & 0.006327 & 3.28 & 2.21 \\
\hline$A^{*} D$ & 1 & 0.00424 & 0.00424 & 2.2 & 1.48 \\
\hline$B{ }^{*}$ & 1 & 0.002562 & 0.002562 & 1.33 & 0.89 \\
\hline$B{ }^{*} D$ & 1 & 0.00762 & 0.00762 & 3.95 & 2.66 \\
\hline$C{ }^{*} D$ & 1 & 0.000005 & 0.000005 & 0 & 0 \\
\hline Residual Error & 13 & 0.025059 & 0.025059 & & 8.74 \\
\hline Total & & & 0.286739 & & 100 \\
\hline
\end{tabular}

\subsection{Conclusion And Recommendation}

The optimal manufacturing conditions and modeling of multiple response of clinical grade $\mathrm{Ti}-13 \mathrm{Zr}-13 \mathrm{Nb}$ alloy using response surface grey relational and regression analysis have been presented in this study. The results showed that the optimal manufacturing conditions to manufacture high grade biomedical Ti$13 \mathrm{Zr}-13 \mathrm{Nb}$ alloy are obtained to be $50 \mathrm{~V}$ voltage, $8 \mathrm{~A}$ current, $6 \mu \mathrm{s}$ pulse $\mathrm{ON}$ time, and $11 \mu \mathrm{s}$ pulse OFF time. These findings conclusively cleared up the uncertain manufacturing conditions presented in the work of Soundhar et al. (2019). It was also shown that the mathematical model was efficacious as the modeled GRG aligned with the experimental one. Furthermore, it was also established that Current was the most significant manufacturing condition with a contribution of $47.27 \%$, however, Voltage, factors interactions and residual error were insignificant on the GRG value of the alloy. In conclusion, inference is that minimum value of voltage could be used to manufacture good grade Ti-13Zr-13Nb alloy and also the small value of residual error showed the high manufacturability of the material.

\section{Declarations}

Funding: This research did not receive any funding 
Conflicts of interest/Competing interests: On behalf of the authors, the corresponding author declares no conflict of interest

Availability of data and material: Not applicable

Code availability: Not applicable

Ethics approval: Not applicable

Consent to participate: Not applicable

Consent for publication: Not applicable

\section{References}

1. Abifarin JK (2021) Taguchi grey relational analysis on the mechanical properties of natural hydroxyapatite: effect of sintering parameters. The International Journal of Advanced Manufacturing Technology, 1-9

2. Abifarin JK, Obada DO, Dauda ET, Dodoo-Arhin D (2019) Experimental data on the characterization of hydroxyapatite synthesized from biowastes. Data in brief 26:104485

3. Abifarin JK, Obada DO, Dauda ET, Oyedeji EO (2021b) Taguchi grey relational optimization of the multi-mechanical characteristics of kaolin reinforced hydroxyapatite: effect of fabrication parameters. Int J Grey Syst

4. Abifarin JK, Prakash C, Singh S (2021c) Optimization and significance of fabrication parameters on the mechanical properties of 3D printed chitosan/PLA scaffold. Materials Today: Proceedings

5. Abifarin JK, Suleiman MU, Abifarin EA, Fidelis FB, Oyelakin OK, Jacob DI, Abdulrahim MY (2021a) Fabrication of mechanically enhanced hydroxyapatite scaffold with the assistance of numerical analysis. The International Journal of Advanced Manufacturing Technology,1-14

6. Boopathi S (2022) An extensive review on sustainable developments of dry and near-dry electrical discharge machining processes. Journal of Manufacturing Science and Engineering, 144(5)

7. Coşkun M, Karahan IH, Yücel Y, Golden TD (2016) Modeling the effect of temperature and potential on the in vitro corrosion performance of biomedical hydroxyapatite coatings. Metall Mater Trans A 47(10):5169-5180

8. Dadrasi A, Fooladpanjeh S, Gharahbagh AA (2019) Interactions between HA/GO/epoxy resin nanocomposites: optimization, modeling and mechanical performance using central composite design and genetic algorithm. Journal of the Brazilian Society of Mechanical Sciences and Engineering 41(2):63

9. Ebrahimi S, Bin Arshad SE (2021) Hydrothermal synthesis of hydroxyapatite powders using Response Surface Methodology (RSM). Plos one, 16(5), e0251009 
10. Eosoly S, Brabazon D, Lohfeld S, Looney L (2010) Selective laser sintering of hydroxyapatite/poly- $\varepsilon$ caprolactone scaffolds. Acta Biomater 6(7):2511-2517

11. Fadli A, Komalasari, Huda F, Ardi T, Habib I (2020) Optimization of Process Condition on Fabrication of Porous Hydroxyapatite Bodies Using Banana Midrib as Template by Response Surface Methodology. Journal of Natural Fibers,1-16

12. Farombi AG, Amuda OS, Alade AO, Okoya AA, Adebisi SA (2018) Central composite design for optimization of preparation conditions and characterization of hydroxyapatite produced from catfish bones. Beni-Suef University journal of basic and applied sciences 7(4):474-480

13. Fern HW, Salimi MN (2021, May) Hydroxyapatite nanoparticles produced by direct precipitation method: Optimization and characterization studies. In AIP Conference Proceedings (Vol. 2339, No. 1, p. 020215). AIP Publishing LLC

14. Foroutan R, Peighambardoust SJ, Aghdasinia H, Mohammadi R, Ramavandi B (2020) Modification of bio-hydroxyapatite generated from waste poultry bone with $\mathrm{MgO}$ for purifying methyl violet-laden liquids. Environ Sci Pollut Res 27(35):44218-44229

15. Garg MP, Sharma A (2017) Examination of accuracy aspect in machining of ZrSiO4p/6063 aluminium MMC using CNC Wire Electrical Discharge Machining. Composites Communications 6:610

16. Gowthaman S, Balamurugan K, Kumar PM, Ali SA, Kumar KM, Gopal NVR (2018) Electrical discharge machining studies on monel-super alloy. Procedia Manufacturing 20:386-391

17. Grigoriev SN, Volosova MA, Okunkova AA, Fedorov SV, Hamdy K, Podrabinnik PA, Porvatov AN (2020) Electrical Discharge Machining of Oxide Nanocomposite: Nanomodification of Surface and Subsurface Layers. Journal of Manufacturing and Materials Processing 4(3):96

18. Kavimani V, Prakash KS, Thankachan T (2019) Influence of machining parameters on wire electrical discharge machining performance of reduced graphene oxide/magnesium composite and its surface integrity characteristics. Composites Part B: Engineering 167:621-630

19. Kumar P, Mahobia GS, Mandal S, Singh V, Chattopadhyay K (2021) Enhanced corrosion resistance of the surface modified Ti-13Nb-13Zr alloy by ultrasonic shot peening. Corrosion Science,109597

20. Li X, Wang Z, Zhang L, Zou C, Dorrell DD (2019) State-of-health estimation for Li-ion batteries by combing the incremental capacity analysis method with grey relational analysis. J Power Sources 410:106-114

21. Majchrowicz A, Roguska A, Pisarek M, Lewandowska M (2019) Nanotubular oxide layers formation on $\mathrm{Ti}-24 \mathrm{Nb}-4 \mathrm{Zr}-8 \mathrm{Sn}$ and $\mathrm{Ti}-13 \mathrm{Zr}-13 \mathrm{Nb}$ alloys in the ethylene glycol-based electrolyte: the role of alloying elements and phase composition. Thin Solid Films 692:137635

22. Ming W, Shen F, Zhang G, Liu G, Du J, Chen Z (2021) Green machining: a framework for optimization of cutting parameters to minimize energy consumption and exhaust emissions during electrical discharge machining of Al 6061 and SKD 11. J Clean Prod 285:124889

23. Montani M, Demir AG, Mostaed E, Vedani M, Previtali B (2017) Processability of pure Zn and pure Fe by SLM for biodegradable metallic implant manufacturing. Rapid Prototyping Journal 
24. Muthuramalingam $T$ (2019) Measuring the influence of discharge energy on white layer thickness in electrical discharge machining process. Measurement 131:694-700

25. Myilsamy S, Sampath B (2021) Experimental comparison of near-dry and cryogenically cooled neardry machining in wire-cut electrical discharge machining processes. Surf Topogr Metrol Prop 9(3):035015

26. Obada DO, Dauda ET, Abifarin JK, Bansod ND, Dodoo-Arhin D (2021a) Mechanical measurements of pure and kaolin reinforced hydroxyapatite-derived scaffolds: A comparative study. Materials Today: Proceedings, 38, 2295-2300

27. Obada DO, Dauda ET, Abifarin JK, Dodoo-Arhin D, Bansod ND (2020) Mechanical properties of natural hydroxyapatite using low cold compaction pressure: Effect of sintering temperature. Mater Chem Phys 239:122099

28. Obada DO, Osseni SA, Sina H, Salami KA, Oyedeji AN, Dodoo-Arhin D, Dauda ET (2021b) Fabrication of novel kaolin-reinforced hydroxyapatite scaffolds with robust compressive strengths for bone regeneration. Appl Clay Sci 215:106298

29. Oladapo BI, Zahedi SA (2021) Improving bioactivity and strength of PEEK composite polymer for bone application. Mater Chem Phys 266:124485

30. Oladapo BI, Zahedi SA, Adeoye AOM (2019) 3D printing of bone scaffolds with hybrid biomaterials. Composites Part B: Engineering 158:428-436

31. Oladapo BI, Zahedi SA, Ismail SO (2021a) Mechanical performances of hip implant design and fabrication with PEEK composite. Polymer 227:123865

32. Oladapo BI, Zahedi SA, Ismail SO, Omigbodun FT (2021b) 3D printing of PEEK and its composite to increase biointerfaces as a biomedical material-A review. Colloids Surf, B 203:111726

33. Oladapo BI, Zahedi SA, Ismail SO, Omigbodun FT, Bowoto OK, Olawumi MA, Muhammad MA (2021c) 3D printing of PEEK-cHAp scaffold for medical bone implant. Bio-Design and Manufacturing 4(1):44-59

34. Ossowska A, Zieliński A, Olive JM, Wojtowicz A, Szweda P (2020) Influence of Two-Stage Anodization on Properties of the Oxide Coatings on the Ti-13Nb-13Zr Alloy. Coatings 10(8):707

35. Pathak DK, Pandey PM (2020) An experimental investigation of the fabrication of biodegradable zinc-hydroxyapatite composite material using microwave sintering. Proceedings of the Institution of Mechanical Engineers, Part C: Journal of Mechanical Engineering Science, 234(14), 2863-2880

36. Prakash C, Uddin MS (2017) Surface modification of $\beta$-phase Ti implant by hydroaxyapatite mixed electric discharge machining to enhance the corrosion resistance and in-vitro bioactivity. Surface and Coatings Technology 326:134-145

37. Prakash C, Singh S, Pabla BS, Uddin MS (2018) Synthesis, characterization, corrosion and bioactivity investigation of nano-HA coating deposited on biodegradable Mg-Zn-Mn alloy. Surface and Coatings Technology 346:9-18

38. Prakash C, Singh S, Pruncu Cl, Mishra V, Królczyk G, Pimenov DY, Pramanik A (2019) Surface modification of Ti-6Al-4V alloy by electrical discharge coating process using partially sintered Ti-Nb 
electrode. Materials 12(7):1006

39. Prakash C, Singh S, Ramakrishna S, Królczyk G, Le CH (2020) Microwave sintering of porous Ti-NbHA composite with high strength and enhanced bioactivity for implant applications. J Alloys Compd $824: 153774$

40. Rizwee M, Minz SS, Orooj M, Hassnain MZ, Khan MJ (1807) Electric discharge machining method for various metal matrix composite materials. International Journal of Innovative Technology and Exploring Engineering 8:9

41. Rizwee M, Rao PS, Khan MY (2020) Recent advancement in electric discharge machining of metal matrix composite materials. Mater Sci $2214: 7853$

42. Shah A, Izman S, Abdul-Kadir MR, Mas-Ayu H (2017) Influence of substrate temperature on adhesion strength of TiN coating of biomedical Ti-13Zr-13Nb alloy. Arabian Journal for Science and Engineering 42(11):4737-4742

43. Singaravel B, Shekar KC, Reddy GG, Prasad SD (2020) Experimental investigation of vegetable oil as dielectric fluid in Electric discharge machining of Ti-6Al-4V. Ain Shams Engineering Journal 11(1):143-147

44. Soundhar A, Zubar HA, Sultan MTBHH, Kandasamy J (2019) Dataset on optimization of EDM machining parameters by using central composite design. Data in brief 23:103671

45. Soundhar A, Zubar HA, Sultan MTBHH, Kandasamy J (2019) Dataset on optimization of EDM machining parameters by using central composite design. Data in brief 23:103671

46. Stanić V, Dimitrijević S, Antonović DG, Jokić BM, Zec SP, Tanasković ST, Raičević S (2014) Synthesis of fluorine substituted hydroxyapatite nanopowders and application of the central composite design for determination of its antimicrobial effects. Appl Surf Sci 290:346-352

47. Świercz R, Oniszczuk-Świercz D (2017) Experimental investigation of surface layer properties of high thermal conductivity tool steel after electrical discharge machining. Metals 7(12):550

48. Tafaoli-Masoule M, Shakeri M, Zahedi SA, Seitz H, Vaezi M (2019) 3D printing of PEEK-based medical devices. Transactions on Additive Manufacturing Meets Medicine, 1(1)

49. Yazdani M, Kahraman C, Zarate P, Onar SC (2019) A fuzzy multi attribute decision framework with integration of QFD and grey relational analysis. Expert Syst Appl 115:474-485

50. Zia MK, Pervaiz S, Anwar S, Samad WA (2019) Reviewing sustainability interpretation of electrical discharge machining process using triple bottom line approach. International Journal of Precision Engineering and Manufacturing-Green Technology 6(5):931-945

\section{Figures}




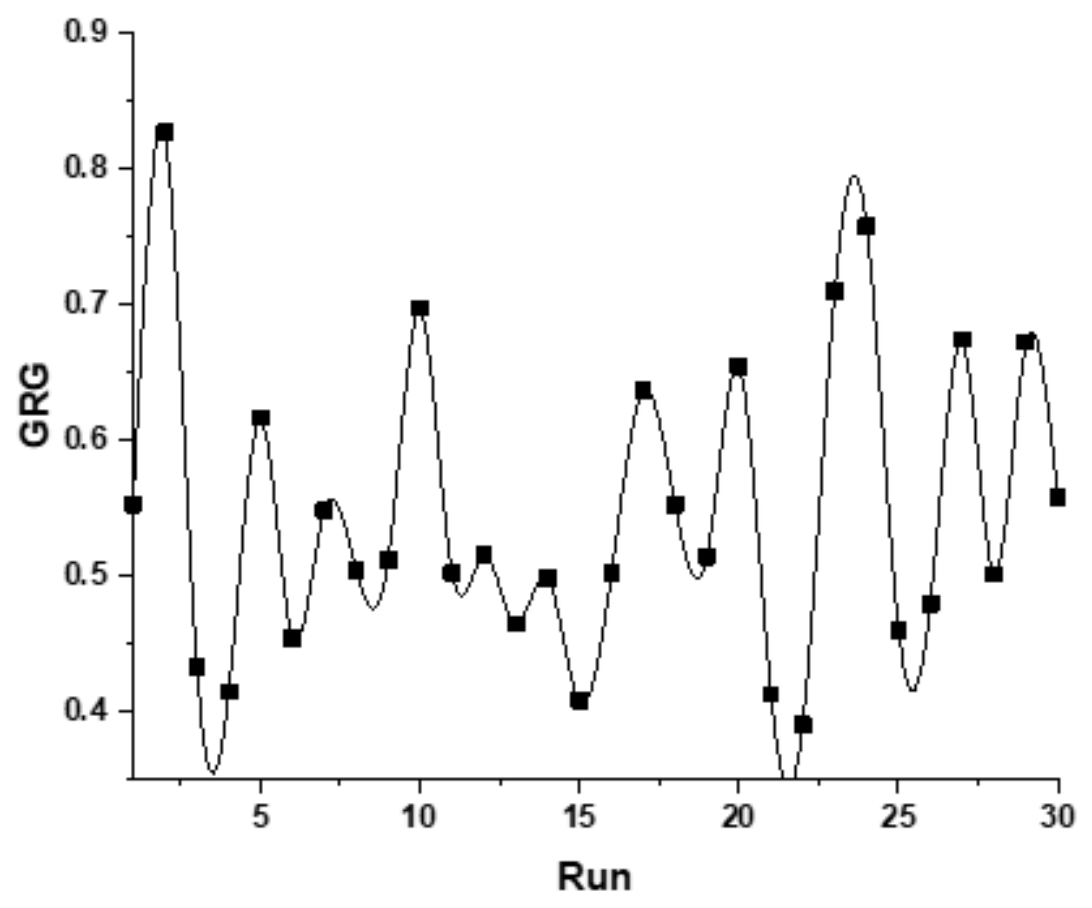

Figure 1

GRG versus run 


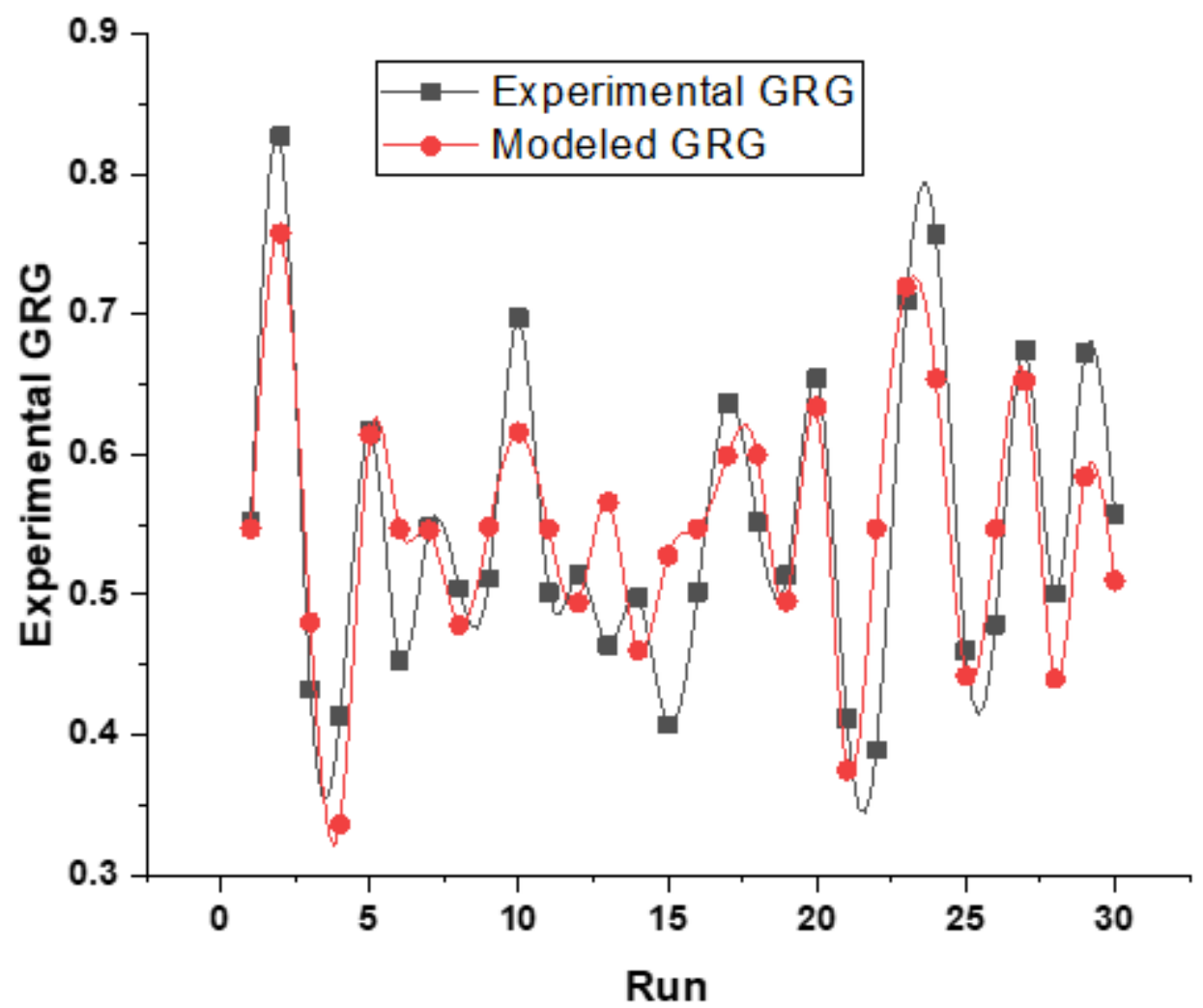

Figure 2

Experimental and modeled GRG values 

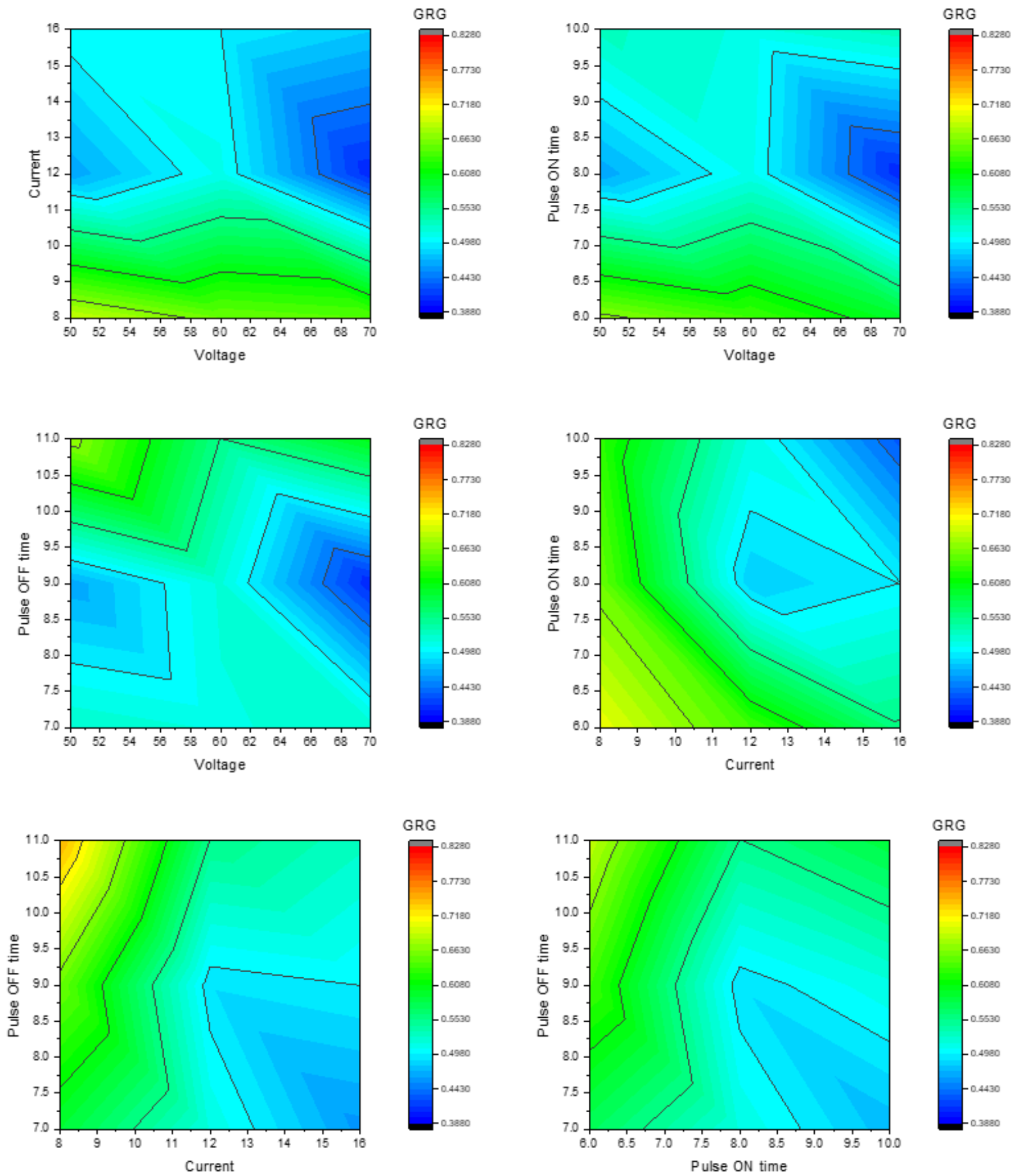

Figure 3

Manufacturing conditions interactions 


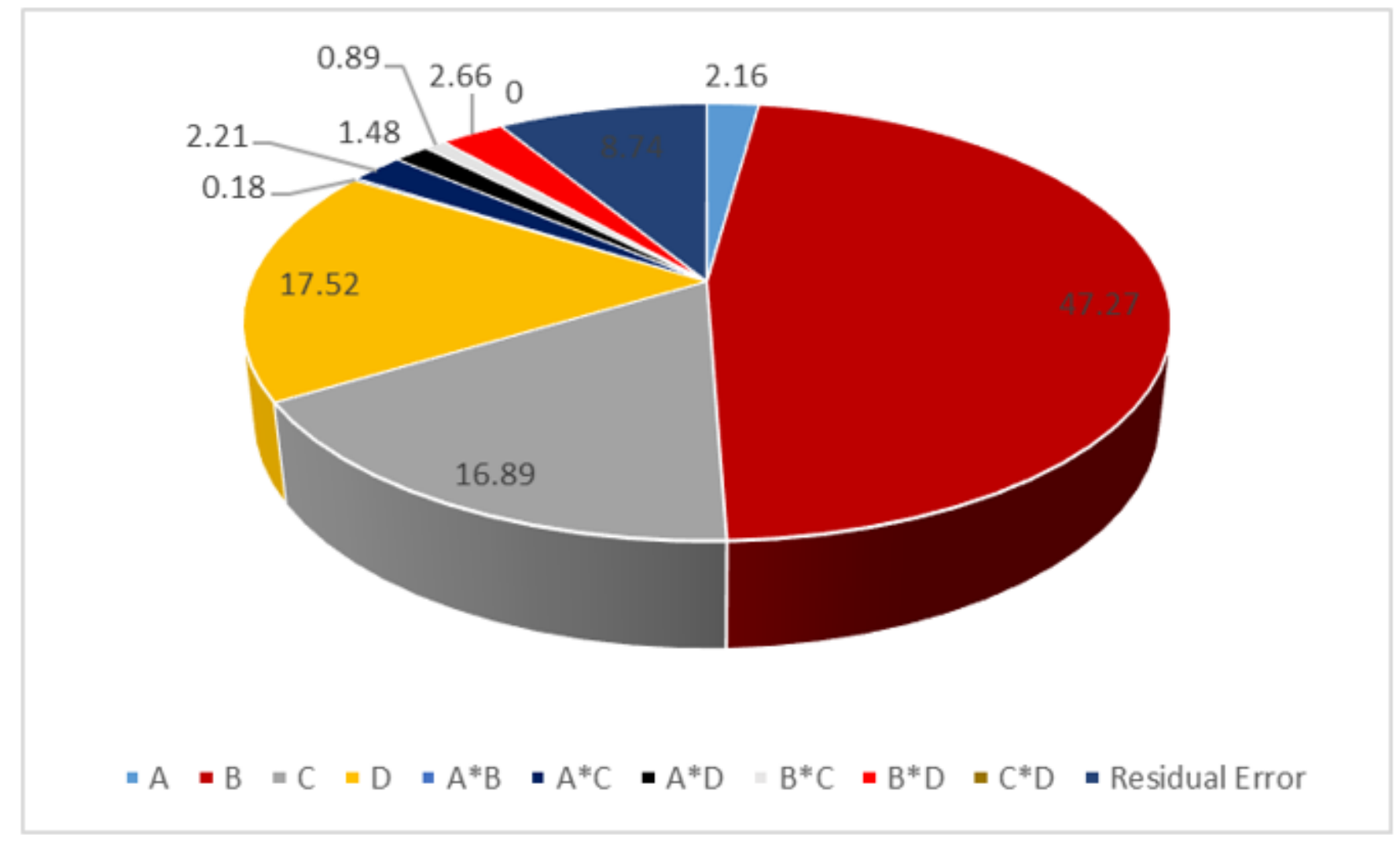

Figure 4

Manufacturing conditions contributions 